\section{Description of male Orthochirus krishnai (Scorpiones: Buthidae) from India, with comments on its taxonomic status}

\author{
Amod M. Zambre ${ }^{1}$ \& D.B. Bastawade ${ }^{2}$ \\ 1 'Saraswati', Gulmohar Path, 72/11 Erandwane, Pune, \\ Maharashtra 411004, India \\ ${ }^{2}$ Zoological Survey of India, Western Regional Station, Pune, \\ Maharashtra 411044, India \\ Email: ${ }^{1}$ amodzambre@gmail.com
}

Buthidae is one of the largest and the most widespread scorpion families. In India, buthids are reported from all over the country with the exception of a few north-eastern states (Tikader \& Bastawade 1983; Rein 2008); and is represented by 54 species from 11 genera and two subfamilies. Members of this family are small to medium-sized with a triangular or pentagonal sternum. In many genera the metasoma is strong and powerful and the pedipalps are slender, whereas some genera have elongated appendages, especially in males (Rein 2008)

The genus Orthochirus Karsch, 1892 consists of small-sized buthids not exceeding 60mm (Kovaøík 2004); Indian forms, however rarely exceed $45 \mathrm{~mm}$ (Tikader \& Bastawade 1983). The genus is characterised by the following set of characterscarapace in lateral view distinctly inclined downwards from the median eyes towards the anterior margin: betaconfiguration in arrangement of trichobothria on the dorsal surface of the pedipalp femur; tibial spurs present on the third and fourth legs; metasomal segments I and II lack carinae; segments IV and V ventrally punctuate: telson elongated, aculeus as long as or longer than vesicle (Tikader \& Bastawade 1983; Kovaøík 2004).

Currently 29 species are included in the genus Orthochirus (Kovaøík 2004; Rein 2008), of which five have been reported from India (Tikader \& Bastawade 1983).

Orthochirus krishnai was described by Tikader \& Bastawade

Date of publication (online): 26 December 2009

Date of publication (print): 26 December 2009

ISSN $0974-7907$ (online) | $0974-7893$ (print)

Editor: Vinod Khanna

\section{Manuscript details:}

Ms \# 02269

Received 28 July 2009

Final received 23 November 2009

Finally accepted 04 December 2009

Citation: Zambre, A.M. \& D.B. Bastawade (2009). Description of male Orthochirus krishnai (Scorpiones: Buthidae) from India, with comments on its taxonomic status. Journal of Threatened Taxa 1(12): 621-623.

Copyright: (c) Amod M. Zambre \& D.B. Bastawade 2009. Creative Commons Attribution 3.0 Unported License. JoTT allows unrestricted use of this article in any medium for non-profit purposes, reproduction and distribution by providing adequate credit to the authors and the source of publication.

Acknowledgments: We are grateful to Dr. Anand Padhye for facilities; Zeeshan Mirza, Ishan Agarwal, N.P.I Das, Shantanu Shukla, Varad Giri, Abi Vanak, and Dharmendra Khandal for suggestions. Kiran Marathe and Tarun Khichi for constant support and encouragement in the field. A.Z. thanks the Khichi family for their hospitality in Sam.

OPEN ACGESS | FREE DOWNLOAD

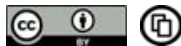

in 1983 based on two female specimens (Registration Nos. NZSI 5077/18 \& $5078 / 18)$ collected in 1972 and 1962 from Rajasthan, western India. Both the specimens are in the National Collections, Zoological Survey of India, Kolkata. Based on the location of $\mathrm{d}_{2}$ trichobothrium on femur illustrated in Tikader \& Bastawade (1983, fig. 361) Kovaøík (2004) considers the species O. krishnai as a nomen dubium.

The present communication deals with the description of one male specimen of O. krishnai collected from Jaisalmer district, Rajasthan with comments on this species

\section{Taxonomy}

Family Buthidae Koch, 1837

Subfamily Buthinae Pocock, 1896

Genus Orthochirus Karsch, 1892

Orthochirus krishnai Tikader \& Bastawade, 1983

1983 Orthochirus krishnai Tikader \& Bastawade, Fauna of India. Scorpions, Scorpionida: Arachnida, Volume III, Zoological Survey of India, $671 \mathrm{pp}$.

Material examined: Male, 10.xi. 2007, (26 $78^{\prime} 451^{\prime \prime} \mathrm{N} \&$ $\left.70^{\circ} 69^{\prime} 542^{\prime \prime} \mathrm{E}\right)$ Nabh Dongar, Jaisalmer District, Rajasthan, India, coll. Amod Zambre, Kiran Marathe, Tarun Khichi and Karan Khichi, (BNHS-Sc-13). The specimen (in 70\% ethanol) is deposited in the collection of the Bombay Natural History Society.

Diagnosis: According to the keys provided in Tikader \& Bastawade 1983, Orthochirus krishnai can be separated from the similar O. melanurus (status unknown) by the presence of a conspicuous yellow triangular spot on the posterior margin of third sternite which is absent in the latter. Femur, patella of legs, and pedipalps dark black or brown and granular in $O$. krishnai while clear yellow in O. melanurus. Ventrally metasomal segments I and II with few pits in the former while pits are absent in the latter.

Description: Male of Orthochirus krishnai Tikader \& Bastawade Colouration: carapace, mesosoma, and metasoma uniformly black; with shades of tan/yellow on the chela, tibia, and tarsus. Telson with a red vesicle and black aculeus.

Prosoma: Carapace entirely black in colour, heavily yet evenly granular without prominent carinae. Median ocular tubercle smooth with a pair of large median eyes situated anteriorly in a ratio of 1:1. Lateral ocular tubercles granular, provided with five pairs (three large anterior and two small posterior) of contiguous lateral eyes situated in a black depression (depression yellow in females).

Mesosoma: Tergites heavily granular, more granular medially and posteriorly. Tergites III-VII with prominent black median carinae (carinae yellow in colour in females). Pretergal portion with very fine granules, black on anterior surface. Tergite VII with four strongly crenulated carinae. Sternites IIV yellowish-brown in colour more granular on the lateral sides, each of them provided with a pair of slit-like stigmata for book lungs. Sternite III with prominent yellow triangular spot. Presternal portion yellow and weakly granular. Sternite V entirely black with four smooth carinae. Pectines well developed, three and a half times as long as wide (six times as long as wide in females). Middle lamellae divided into seven 


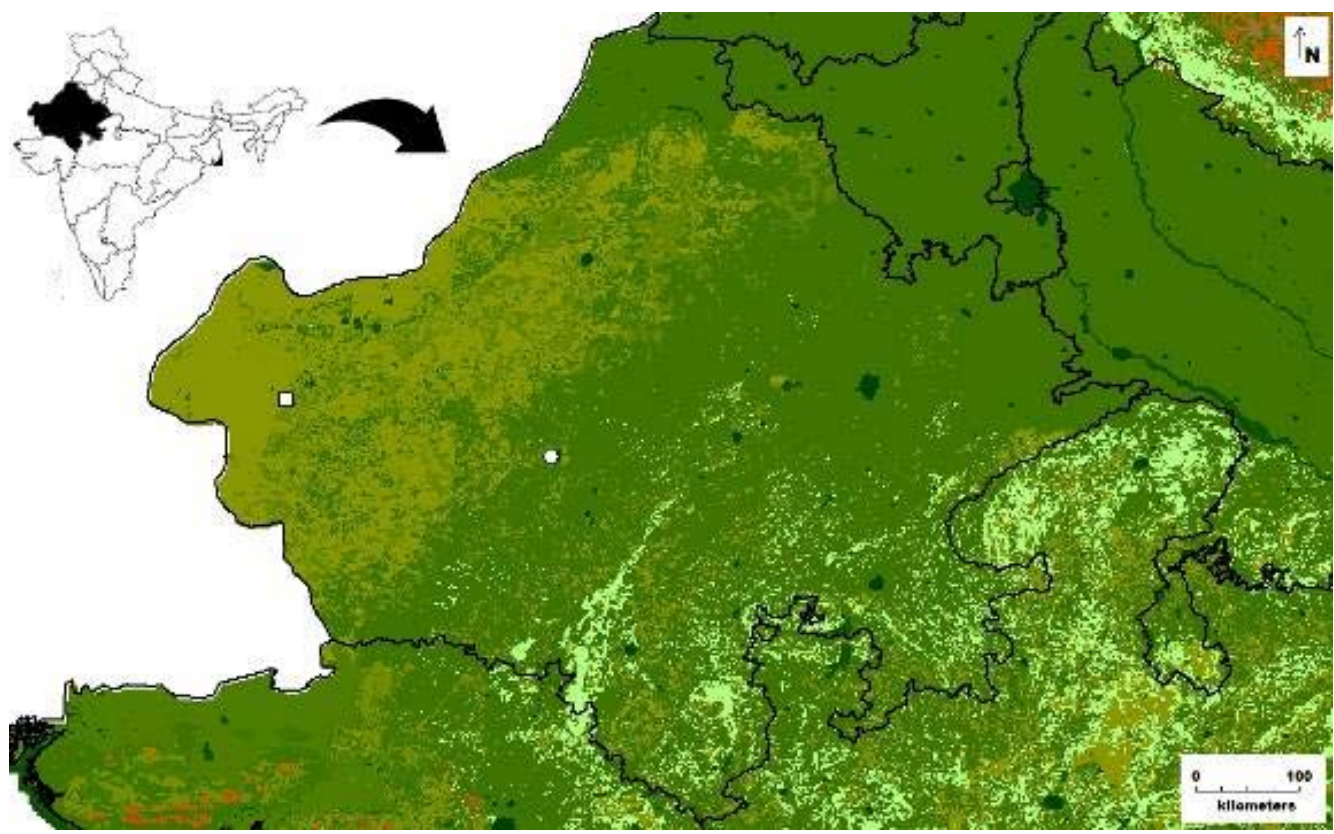

Map of Rajasthan showing the type locality of Octhochius krishnai Jodhpur (white circle) and Nabh Dongar (white square)

Table 1. Morphometrics of male Orthochirus krishnai recorded with a vernier caliper $( \pm 0.01 \mathrm{~mm})$

\begin{tabular}{ll}
\hline \multicolumn{1}{c}{ Character } & Orthochirus krishnai \\
\hline (BNHS-Sc-13) (in mm) & \\
Carapace length & 4 \\
Carapace anterior width & 2.82 \\
Carapace posterior width & 4.77 \\
Mesosoma & 9.18 \\
Metasoma & 18.12 \\
I segment length & 2.24 \\
I segment width & 3.58 \\
II segment length & 2.7 \\
II segment width & 3.44 \\
III segment length & 3.28 \\
III segment width & 4.36 \\
IV segment length & 4.88 \\
IV segment width & 4.66 \\
V segment length & 5.02 \\
V segment width & 5.22 \\
Vesicle width & 1.45 \\
Vesicle length & 3.23 \\
Aculeus length (broken) & 1.32 \\
Femur length & 4.60 \\
Femur width & 0.66 \\
Patella length & 4.87 \\
Patella width & 1.38 \\
Chela length & 5.18 \\
Movable finger & 4.40 \\
\hline
\end{tabular}

digits (middle lamellae divided into eight digits in females). Fulcra distinct. Lamellae and fulcra provided with minute red setae. Pectinal teeth 23/23 in number. Basal piece granular. Genital operculum partially separated (united in females).

Metasoma: Black, thick and incrassate. Segment I with all ten carinae, carinae crenulate, intercarinal spaces finely granular and provided with few pits. Segments II and III with dorsal and inferior carinae. Segment IV smooth covered with pits with very weakly developed dorsal and inferior carinae. Segment V densely pitted with weakly developed lateral inferior. Anal rim smooth. Vesicle reddish, pyriform, elongated, smooth and slender covered with few pits. Aculeus short and black (broken in the specimen).

Chelicerae: Chelicera strong, basal segment black in color



Image 1. Orthochirus krishnai

(darker on anterior portion while paler on ventral side). Fingers of chelicera dark in color and reddish on dentition.

Pedipalps: Femur and patella of pedipalp dark black (femur darker than patella). Manus yellowish-brown with blackish tint (fig. 354 of Tikader \& Bastawade 1983:131) with clear yellow fingers. Dentition non-imbricate and movable finger with nine teeth in the outer row. Trichobothrial pattern Type A on femur, patella and chela as per (fig. 1-6 of Kovarik 2004:5). Coxa, trochanter and femur of leg black in colour. Patella also black in color with a yellow tint to it. Tibia and tarsomere I yellow with a prominently visible black carinae. Tarsomere II clear yellow.

\section{Discussion}

Orthochirus krishnai was considered nomen dubium by Kovaøík (2004) solely on the position of $\mathrm{d} 2$ trichobothrium on the dorsal surface of the femur after referring to the illustration provided in Tikader and Bastawade (see fig. 361 1983:132) as he could not study the type material. Kovaøík (2004) also suggested 
placing O. krishnai in the genus Paraorthochirus Lourenco \& Vachon, 1995 instead of Orthochirus. Kovaøík (2004) also states that the original description was inadequate but did not elucidate in what aspects the description was lacking.

Navidpour et al. (2008), after studying numerous specimens of $O$. iranus, concluded that the status of trichobothrium $\mathrm{d} 2$ is variable (fully developed, reduced, or absent). As presence or absence of $\mathrm{d} 2$ was the only character separating Orthochirus and Paraorthochirus, Navidpour et al. (2008) synonymized the two genera transferring all species from Paraorthochirus to Orthochirus. In the light of the recent taxonomic changes and the occurrence of a specimen of O. krishnai, we consider $O$. krishnai a valid species.

The types described were from Jodhpur District, Rajasthan whereas the present male specimen was collected from Jaisalmer district, Rajasthan, approximately $250 \mathrm{~km}$ northwest of the type locality, indicating a wide distribution in Rajasthan.

\section{References}

Kovaøík, F. (2004). Revision and taxonomic position of general Afghanorthochirus Lourenço and Vachon, Baloorthochirus Kovaøík, Butheolus Simon, Nanobuthus Pocock, Orthochiroides Kovaøík, Pakistanorthochirus Lourenço, and Asian Orthochirus Karsch, with description of twelve new species (Scorpiones, Buthidae). Euscorpius 16: $1-33$.

Rein, J.O. (2008). Scorpion Files. Norwegian University of Science and Technology, online at; http://www.ub.ntnu.no/scorpion-files.

Navidpour, S., F. Kovaøík, M.E. Soleglad \& V. Fet (2008). Scorpions of Iran (Arachnida, Scorpiones). Part I. Khoozestan Province. Euscorpius 65: $1-41$.

Tikader, B.K. \& D.B. Bastawade. (1983). The Fauna of India. Scorpions, Scorpionida: Arachnida, Volume III, Zoological Survey of India, 671pp. 